\title{
Investigating the learning perspective of Searching as Learning, a review of the state of the art
}

\author{
Paulo J. A. Gimenez, Marcelo Machado, Cleber Pinelli, Sean W. M. Siqueira \\ ${ }^{1}$ Programa de Pós-Graduação em Informática (PPGI) \\ Universidade Federal do Estado do Rio de Janeiro (UNIRIO) \\ Av. Pasteur, 456, Urca - Rio de Janeiro - RJ - Brasil \\ \{paulo.gimenez, marcelo.machado\}@edu.unirio.br \\ \{cleber.pinelli, sean\}@uniriotec.br
}

\begin{abstract}
Current search engines are not designed to facilitate learning as they do not lead the user to develop more complex skills. Searching as Learning (SAL) emerged as a research area from the intersection of information search and learning technologies in order to advance the study of searching as a learning process. However, we wonder how have the learning theories and approaches been explored in SAL. Through a systematic review of the literature, we identified 65 papers that report SAL solutions. We analyzed them, seeking to answer (i) which learning theories, approaches and methods support the searching as a learning process, and (ii) what metrics, procedures, or treatments were used to measure learning during the searching process. We uncover the learning perspective in the SAL literature, discussing the learning paradigms, the mechanisms influencing the learning process, the search session design for learning, and the knowledge gain measurement strategies.
\end{abstract}

\section{Introduction}

Performing search tasks to acquire new skills and knowledge is a commonplace. In distance and remote education (Cho and Shen, 2013), the use of search systems become indispensable due to the shift from a physical space of social interaction to a digital space. Coronavirus emergence has raised the need for a transformation in education, which is intensively supported by educational technology (Williamson et al., 2020). Searching as Learning (SAL) is a recent research area that considers issues involving learning during the search process (Moraes et al., 2018). It focuses on the impact, influence, and consequences of using search engines as learning technologies (Machado et al., 2019).

There are two main tasks performed by learners while using search systems, the decision-making process of formulating and reformulating queries (Liu et al., 2010); and the navigation where the learner interacts with information (Herder and Juvina, 2004). In the first task, the learner has to properly use the key terms to retrieve relevant information and develop successful search strategies. In the second task, the learner is responsible for selecting the sources. He should be able to identify reliable sources and to establish relationships between concepts to process information towards knowledge construction. The dynamics of these two tasks contribute to learning as the learner is engaged in his process. Knowledge gain in this context comes from web search behavior and information use analysis (Wilson, 1999). 
Information retrieval and interaction communities have supported the understanding of the learning process during search tasks as well as the development of search engines that target learning outcomes (Rieh et al., 2016). Vakkari (2016) surveyed empirical studies on the relationship between information searching and learning. On the same perspective, Rieh et al. (2016) critically reviewed the literature, highlighting the learning process during the search process, focusing on critical and creative thinking. Then, Hoppe et al. (2018) reinforced the current challenges of a SAL agenda, over information retrieval and psychopedagogy perspectives. Marchionini (2018) reviewed historical aspects of the learning literature, giving attention to learning theories and highlighting changes that occur on neural, cognitive, affective, and behavioral dimensions. Machado et al. (2019) revealed the presence of few studies rooted in learning theories in SAL, which may represent a research gap. SAL is an approach that suits better for informal learning perspective. However, in order to incorporate this approach to distance education, the supervision of learner's progress is necessary, since learning assessment is an important step in formal education. In this context, detecting, measuring, and predicting knowledge gain (Gadiraju, 2018; Gadiraju et al., 2018) in SAL situations might become the focus due to the current pandemic crisis. For that reason, the understanding of learning theories and the mechanisms to estimate learning progress are important research issues for SAL.

Through a systematic review protocol, we identified 65 research papers that presented studies with solutions that support search as a learning process. Then, we listed some findings from the analysis of these studies considering: (i) learning theories are used to understand and define the learning process, with emphasis on the use of the main known approaches such as behaviorism, cognitivism and constructivism; and (ii) the techniques used to measure knowledge gain in searching as a learning process, including learner's metacognition, search success performance, and predictive model analysis.

The remaining of this paper is organized as follows: Section 2 presents the systematic review methodology; Section 3 presents and analyzes the learning approaches and techniques by the literature review in SAL; Section 4 deals with issues related to the threat of validity of the present work. Finally, Section 5 concludes the paper and develops some perspectives of future work.

\section{Methodology}

The purpose of this systematic literature review is to identify, evaluate and report the available studies considering the research questions (Kitchenham and Charters, 2007). This review was organized based on the main activities proposed by Kitchenham and Charters (2007): planning, conducting and reporting the study.

The systematic review aims to answer the following research questions:

- RQ1: Which learning theories, approaches and methods support the search as a learning process?

- RQ2: What metrics, procedures and treatments are used to measure learning during a searching process?

The Selection Criteria process used three exclusion criteria (EC):

- EC1: The paper does not deal with the SAL context or learning associated with the search process OR 
IX Congresso Brasileiro de Informática na Educação (CBIE 2020)

Anais do XXXI Simpósio Brasileiro de Informática na Educação (SBIE 2020)

- EC2: The paper was not published in a peer-review conference, event or journal OR

- EC3: The paper was not written in the English language.

Then the search query was formulated and executed in eight digital libraries, as presented in Table 1.

Initially, to create the search string, we considered the research questions, and the scope was defined using the PICOC method (Petticrew and Roberts, 2008): Population="Web Search", Intervention = "Search as Learning", Comparison="", Outcome="Solutions" and Context="Education"). Therefore, we intended to evaluate Searching as Learning proposals in Web-based settings that were proposed with an educational purpose. However, as SAL is a rather new research agenda, we only considered Intervention terms and their alternate spelling and synonyms, not applying other filters that could leave some sort of solutions out of the analysis. Then, an initial string was formed considering synonyms and alternate spellings from the intervention term, concatenated using Boolean OR operator. A set of potential primary studies were also defined to validate the search string accuracy in the selected databases and check whether the search retrieved the verification studies. The final search string was defined as follows:

("Search as Learning" OR "Searching as Learning" OR "Search as a Learning" OR

"Searching as a Learning" OR "Learning on Search" OR "Learning on Searching")

The platform Parsif.al ${ }^{1}$ was used to catalog the papers and manage the selection activity (Kitchenham and Charters, 2007). The systematized process covered objectives, PICOC items, research questions, search string, keywords and synonyms, selecting the sources, inclusion and exclusion criteria collected during Nov-Dec/2019. The process comprised the following steps:

Step 1 The execution of the search string, considering the selected sources.

Step 2 The merge of the results from all databases and removal of duplicates.

Step 3 The evaluation of the papers based on their titles and abstracts, considering the selection criteria.

Step 4 The evaluation of the papers based on their introduction and conclusion, considering the selection criteria.

Step 5 The full reading of the papers and their analysis, considering the research and mapping questions.

First, each paper was evaluated by two researchers. In the case of divergence, a third researcher was assigned to the evaluation. Only papers accepted by two researchers were considered.

With the final search string applied in all sources, a set of 577 papers was obtained in Step 1. In Step 2, the duplicated papers were removed, and a set of $461(79.89 \%)$ papers remained. After reviewing the titles and abstracts, in Step 3, 104 (18.02\%) papers were included. After evaluating the introduction and conclusion of each paper in step 4, only $65(11.26 \%)$ remained and were accepted to the next stage (Step 5).

\footnotetext{
${ }^{1}$ https://parsif.al/
} 
IX Congresso Brasileiro de Informática na Educação (CBIE 2020)

Anais do XXXI Simpósio Brasileiro de Informática na Educação (SBIE 2020)

Table 1. Results of the systematic conduction process.

\begin{tabular}{|c|c|c|c|c|c|}
\hline Source & & Step 1 & Step 2 & Step 3+4 & Step 5 \\
\hline Name & URL & & (duplicates) & (removed by criteria) & \\
\hline ACM Digital Library & https://dl.acm.org/dl.cfm & 13 & 12 & 0 & 1 \\
\hline El Compendex & http://www.engineeringvillage.com & 36 & 21 & 4 & 11 \\
\hline GoogleScholar & https://scholar.google.com & 297 & 39 & 228 & 38 \\
\hline IEEE Digital Library & http://ieeexplore.ieee.org & 2 & 2 & 0 & 0 \\
\hline ISI Web of Science & http://www.isiknowledge.com & 14 & 10 & 4 & 0 \\
\hline Science@Direct & https://www.sciencedirect.com & 144 & 3 & 137 & 4 \\
\hline Scopus & http: //www.scopus.com & 31 & 21 & 3 & 7 \\
\hline \multirow[t]{2}{*}{ Springer Link } & http://link.springer.com & 33 & 8 & 21 & 4 \\
\hline & Total & 577 & 116 & 396 & 65 \\
\hline
\end{tabular}

\section{The learning side of Searching as Learning}

Since there is not a unique definition for learning or a unique way to assess it, SAL may be seen according to the set of theories and pedagogical principles guiding the learning process. There are different approaches applied to comprehend the human mind as paradigms. Learning theories were created under these paradigms. Even having antagonistic comprehension of learning, one theory does not invalidate another, and they complement and refine educational practices (Schunk, 1991). Learning approaches result from the attempts of psychologists to organize observations, hypotheses, cues, laws, principles and suppositions that have been presented from human behavior (Lefrancois, 2012).

Picciano (2017) examined theoretical frameworks and models focused on online education. In that work, Behaviorism is described with a focus on how people behave, while Cognitivism is based on the concept where the mental process has an important role in learning, establishing the connection between environmental stimuli and the individual's responses. Constructivism, represented mainly by Vygotsky and Piaget, has a focus on the individual's development, where knowledge is constructed as a result of individual experience or social interaction (Lefrancois, 2012).

In order to answer RQ1, some analyses were done to identify and correlate the dimensions of macro learning approaches, the mechanisms that influence learning, and session design to structuring the environment and the interaction that supports learning. These elements of analysis were structured and collected based on the learning approaches perspective (Picciano, 2017). The panel of learning factors influencing searching as learning was also considered (Hansen and Rieh, 2016).

1. Learning Paradigms (LP): Represents sets of principles, statements or ideas that define, explain or predict learning. It supports the understanding of how people learn. Some studies explicitly declare the learning paradigm they are using, such as Liu and Song (2018), who constructed two types of learning-related tasks according to the first two levels of Cognitive Learning Mode classification (Lee et al., 2015). On the other hand, some other studies had the learning paradigm inferred based on their characteristics, as they do not mention it, such as Han et al. (2019), who explored mental models and dimensions of cognition and emotion. Table 2 summarizes the studies according to these paradigms that are predominantly represented based on our analysis.

2. Mechanisms Influencing Learning Process (MILP): Represents the features, elements or actions used to influence or stimulate learning. From the behavioral perspective, the use of techniques to reinforce search behavior, which is learningrelated (Harasim, 2011). From the cognitivist perspective, it is usually concerned 
IX Congresso Brasileiro de Informática na Educação (CBIE 2020)

Anais do XXXI Simpósio Brasileiro de Informática na Educação (SBIE 2020)

Table 2. Summary of the studies according to learning paradigms.

\begin{tabular}{|c|c|}
\hline LP & Studies \\
\hline Behaviorist & $\begin{array}{l}\text { (Lu and Hsiao, 2017), (Zhuang et al., 2016), (Mao et al., 2016), (Moraes et al., 2018), (Wilson and Wilson, } \\
\text { 2013) }\end{array}$ \\
\hline Cognitivist & $\begin{array}{l}\text { (Kodama et al., 2017), (Moraes et al., 2018), (Taibi et al., 2017), (Wilson et al., 2016), (Syed and Collins- } \\
\text { Thompson, 2016), (Bhattacharya and Gwizdka, 2019), (Al-Tawil et al., 2019), (Azpiazu et al., 2017), } \\
\text { (Crescenzi, 2016), (Han et al., 2019), (Liu and Song, 2018), (Johnson, 2018), (Jansen et al., 2007), (Smith } \\
\text { and Rieh, 2019) }\end{array}$ \\
\hline Constructivist & $\begin{array}{l}\text { (Ghosh et al., 2018), (Tibau et al., 2018b), (Freund et al., 2016), (Komlodi and Caidi, 2016), (Weingart and } \\
\text { Eickhoff, 2016), (Tibau et al., 2018a), (Yu et al., 2018b), (Al-Tawil et al., 2019) (Ibieta et al., 2019), (Zapata } \\
\text { et al., 2015), (Zhang, 2017), (Meyers, 2018), (Cho et al., 2017), (Vakkari et al., 2019), (Ibieta et al., 2019) }\end{array}$ \\
\hline
\end{tabular}

about information processing, search complexity and cognitive effort. From the constructivist perspective, it can be focused on what the learner can or cannot do without help, known as the zone of proximal development (Vygotsky et al., 1978). Some studies explore the participants' engagement; the evaluation as a motivator during the sessions; the teacher intervention during the session (Han et al., 2019); reordering of the search results page to support learning (Teixeira et al., 2020) (Pinelli et al., 2019); judgments and interventions and interventions on search systems to improve the learning experience (Syed and Collins-Thompson, 2016); web document features and the relationship with short or long-term learning outcomes (Syed and Collins-Thompson, 2018). Table 3 summarizes papers according to the mechanisms influencing the learning process in the literature.

Table 3. Summary of the studies according to mechanisms that influence the learning process.

\begin{tabular}{|l|l|}
\hline MILP & Studies \\
\hline $\begin{array}{l}\text { Reinforcements } \\
\text { Rewards }\end{array}$ & $\begin{array}{l}\text { (Zapata et al., 2015) } \\
\text { (Taibi et al., 2017), (Gadiraju, 2018), (Zhuang et al., 2016), (Yu et al., 2018a), (Gadiraju et al., } \\
\text { 2018) } \\
\text { Evaluation }\end{array}$ \\
(Rieh et al., 2012), (Tibau et al., 2018b), (Liu and Song, 2018), (Johnson, 2018), (Smith and Rieh, \\
2019), (Wilson and Wilson, 2013), (Vakkari et al., 2019) \\
Assistance or guidance \\
$\begin{array}{l}\text { (Han et al., 2019), (Hinostroza et al., 2018), (Cho et al., 2017), (Moraes et al., 2018), (Ibieta et al., } \\
\text { 2019) }\end{array}$
\end{tabular}

3. Session Design for Learning (SDL): Represents the structural, environmental and interactive features of the session that are used to support and ensure learning. Under the lens of what learning is and how it occurs during an online search session, we are concerned about how session design features provide important information about what makes students more effective. These features are related to session control (Han et al., 2019), sharing (Meyers, 2018) and the kind of assistance. The search process environment converges to the learning process in some ways, such as an effective learning environment with a community-centered, knowledge-centric, student-centric, or overlapping (Anderson, 2011). Table 4 summarizes the papers according to the SDL perspective.

\section{Recognizing Knowledge Gain}

A major challenge of recognizing knowledge gain is through metrics, which is the topic of RQ2. Along with the evolution of the search mechanisms, ways to assess its processes 
IX Congresso Brasileiro de Informática na Educação (CBIE 2020)

Anais do XXXI Simpósio Brasileiro de Informática na Educação (SBIE 2020)

Table 4. Summary of the studies according to sessions designed for learning.

\begin{tabular}{|l|l|}
\hline SDL & Studies \\
\hline Controlled Session & $\begin{array}{l}\text { (Kodama et al., 2017), (Freund et al., 2016), (Azpiazu et al., 2017), (Gadiraju, 2018), (Komlodi } \\
\text { and Caidi, 2016), (Mao et al., 2016), (Weingart and Eickhoff, 2016), (Bhattacharya and Gwizdka, } \\
\text { 2019) (Han et al., 2019), (Hinostroza et al., 2018), (Gadiraju et al., 2018), (Gadiraju et al., 2018), } \\
\text { (Cho et al., 2017), (Wilson and Wilson, 2013), (Ibieta et al., 2019) } \\
\text { (Han et al., 2019), (Johnson, 2018), (Vakkari et al., 2019) }\end{array}$ \\
Not Controlled Session & $\begin{array}{l}\text { (Han et al., 2019), (Meyers, 2018), (Gadiraju et al., 2018), (Gadiraju et al., 2018), (Cho et al., } \\
\text { 2017), (Wilson and Wilson, 2013), (Vakkari et al., 2019), (Ibieta et al., 2019) } \\
\text { (Meyers, 2018), (Moraes et al., 2018) }\end{array}$ \\
\hline Individual Session & $\begin{array}{l}\text { (Liu and Song, 2018) } \\
\text { (Yu et al., 2018a), (Tibau et al., 2018b), (Zapata et al., 2015), (Gadiraju et al., 2018), (Smith and } \\
\text { Rieh, 2019), (Wilson and Wilson, 2013) } \\
\text { (Han et al., 2019), (Meyers, 2018), (Gadiraju et al., 2018), (Moraes et al., 2018), (Vakkari et al., } \\
\text { 2019), (Ibieta et al., 2019) } \\
\text { (Jansen et al., 2007), (Cho et al., 2017) }\end{array}$ \\
\hline
\end{tabular}

and interactions have emerged. We analyzed recent studies on how to estimate learning, identifying what we call as Measurement Records of Learning (MRL). It represents mechanisms and methods employed to indicate learning gains during search sessions by extracting data from interviews, search logs, self-reports, video recording, and pre and post-tasks (Gadiraju et al., 2018). It may involve predictive analysis, cognitive models, ontology and knowledge representation.

Predictive models, cognitive representation of search tasks and other methods may support the assessment of knowledge gain. Han et al. (2019) proposed a classification system for novice users' mental models. Tibau et al. (2018b) investigated the decisionmaking process, which supports the understanding of the learner's progress. Classical evaluations still predominate to measure the learning gain during the search process, evidenced by the use of pre- and post-session tests (Meyers, 2018). Liu and Song (2018) evaluated the knowledge points captured before and after the search tasks. Jansen et al. (2007) proposed the use of Anderson and Krathwohl's Taxonomy of the cognitive domain and (Anderson et al., 2001) the revised Bloom's Taxonomy of Educational Objectives. Alternatively, Moraes et al. (2018) used a vocabulary of learning tasks, and Smith and Rieh (2019) used metacognitive analysis to understand the knowledge-context enriching from retrieval results. Table 5 presents a summary according to MRL we identified.

Table 5. Classification of Measurement records of learning (MRL).

\begin{tabular}{|l|l|}
\hline MRL & Studies \\
\hline Pre and post-tests & (Rieh et al., 2012), (Meyers, 2018), (Gadiraju et al., 2018), (Cho et al., 2017) \\
Assisted Process & (Johnson, 2018), (Hinostroza et al., 2018), (Vakkari et al., 2019), (Ibieta et al., 2019) \\
Knowledge base & (Yu et al., 2018a), (Tibau et al., 2018b), (Liu and Song, 2018), (Gadiraju et al., 2018) \\
Ontologies or taxonomies & (Jansen et al., 2007), (Moraes et al., 2018), (Wilson and Wilson, 2013) \\
Cognition or mind models & (Han et al., 2019), (Smith and Rieh, 2019) \\
\hline
\end{tabular}

\section{Concluding Remarks}

Searching as Learning nowadays is pervasive in formal, informal and lifelong learning. Particularly, in distance (and remote) education, where the learner needs to be more engaged in the tasks, it raises the need for understanding and supervising this process. Then, mechanisms to evaluate learning progress must perform well in order to search as learning be considered as a reasonable strategy for pedagogical architecture. According to our view, learning theories and approaches should guide the development of the area in order to align with educational practices. 
This paper presented a systematic literature review on SAL, focused on analyzing the different solutions for search as learning. The selected papers were analyzed based on two research questions: (i) the learning theories and paradigms that have been used, either directly cited or inferred from our analysis, and (ii) how knowledge gain has been measured in these studies. We believe that these items are of essential importance for connecting SAL with other areas of information systems for education, such as Learning Analytics and Educational Data Mining.

As future work, we consider a further analysis of learning theories and approaches according to education-related research areas to reinforce the importance of developing techniques to support learning. As a result, it would be possible to identify the intersection of the learning aspects applied by such approaches with the elements of the search process, highlighting which ones combine successfully or not to promote measurable learning gains. This correlation would guide the combination of new or revised learning approaches with more advanced search engines.

\section{Acknowledgment}

This study was financed in part by the 'National Council for Scientific and Technological Development (CNPq) - Brazil' - Process 315374/2018-7, Project 'Searching as Learning: the information search as a tool for learning' and by the 'Coordination for the Improvement of Higher Education Personnel' (CAPES) - Brazil - Finance Code 001

\section{References}

Al-Tawil, M., Dimitrova, V., and Thakker, D. (2019). Using knowledge anchors to facilitate user exploration of data graphs. Semantic Web, pages 1-30.

Anderson, L. W., Krathwohl, D. R., Airasian, P., Cruikshank, K., Mayer, R., Pintrich, P., Raths, J., and Wittrock, M. (2001). A taxonomy for learning, teaching and assessing: A revision of bloom's taxonomy.

Anderson, T. (2011). The theory and practice of online learning. AU Press, Athabasca University, Edmonton, Canada, 2th edition.

Azpiazu, I. M., Dragovic, N., Pera, M. S., and Fails, J. A. (2017). Online searching and learning: Yum and other search tools for children and teachers. Information Retrieval Journal, 20:524-545.

Bhattacharya, N. and Gwizdka, J. (2019). Measuring learning during search: Differences in interactions, eye-gaze, and semantic similarity to expert knowledge. In Proceedings of the 2019 Conference on Human Information Interaction and Retrieval, pages 63-71. ACM.

Cho, B.-Y., Woodward, L., Li, D., and Barlow, W. (2017). Examining adolescents' strategic processing during online reading with a question-generating task. American Educational Research Journal, 54:691-724.

Cho, M.-H. and Shen, D. (2013). Self-regulation in online learning. Distance Education, 34(3):290-301.

Crescenzi, A. (2016). Metacognitive knowledge and metacognitive regulation in timeconstrained in information search. In SAL@ SIGIR, volume 1647.

Freund, L., Kopak, R., and O'Brien, H. (2016). The effects of textual environment on reading comprehension: Implications for searching as learning. Journal of Information Science, 42:79-93. 
IX Congresso Brasileiro de Informática na Educação (CBIE 2020)

Anais do XXXI Simpósio Brasileiro de Informática na Educação (SBIE 2020)

Gadiraju, U. (2018). A new age of search systems by ujwal gadiraju with martin vesely as coordinator: understanding knowledge gained by users through search. ACM SIGWEB Newsletter, page 4.

Gadiraju, U., Yu, R., Dietze, S., and Holtz, P. (2018). Analyzing knowledge gain of users in informational search sessions on the web. In Proceedings of the 2018 Conference on Human Information Interaction \& Retrieval, pages 2-11. ACM.

Ghosh, S., Rath, M., and Shah, C. (2018). Searching as learning: Exploring search behavior and learning outcomes in learning-related tasks. In Proceedings of the 2018 Conference on Human Information Interaction \& Retrieval, pages 22-31.

Han, Z., Hansen, P., Xu, H., and Luo, R. (2019). Examining the classification and evolution of novice users' mental models of an academic database in the search task completion process. Journal of Information Science.

Hansen, P. and Rieh, S. Y. (2016). Recent advances on searching as learning: An introduction to the special issue.

Harasim, L. (2011). Learning Theory and Online Technologies. Routledge, New York, NY, 10001, 1st edition.

Herder, E. and Juvina, I. (2004). Discovery of individual user navigation styles. Proc. Workshop on Individual Differences in Adaptive Hypermedia, Held at AH2OO4.

Hinostroza, J. E., Ibieta, A., Labbé, C., and Soto, M. T. (2018). Browsing the internet to solve information problems: A study of students' search actions and behaviours using a 'think aloud'protocol. Education and Information Technologies, 23:1933-1953.

Hoppe, A., Holtz, P., Kammerer, Y., Yu, R., Dietze, S., and Ewerth, R. (2018). Current challenges for studying search as learning processes. In 7th Workshop on Learning \& Education with Web Data (LILE2018), in conjunction with ACM Web Science 2018, Amsterdam, NL, 27 May, 2018.

Ibieta, A., Hinostroza, J. E., and Labbé, C. (2019). Improving students' information problem-solving skills on the web through explicit instruction and the use of customized search software. Journal of Research on Technology in Education, pages 1-22.

Jansen, B. J., Smith, B., and Booth, D. (2007). Learning as a paradigm for understanding exploratory search. ESI 2007, page 72.

Johnson, F. (2018). From accessibility to assess-ability: An evaluation heuristic based on cognitive engagement in search. In International Conference on Information, pages 487-497. Springer.

Kitchenham, B. and Charters, S. (2007). Guidelines for performing systematic literature reviews in software engineering. Information and software technology.

Kodama, C., Jean, B. S., Subramaniam, M., and Taylor, N. G. (2017). Thereś a creepy guy on the other end at google!: engaging middle school students in a drawing activity to elicit their mental models of google. Information Retrieval Journal, 20:403-432.

Komlodi, A. and Caidi, N. (2016). Learning in second-language searching. In SAL@ SIGIR, volume 1647 .

Lee, H.-J., Lee, J., Makara, K. A., Fishman, B. J., and Hong, Y.-I. (2015). Does higher education foster critical and creative learners? an exploration of two universities in south korea and the usa. Higher Education Research \& Development, 34(1):131-146.

Lefrancois, G. (2012). Theories of Human Learning: What the Professor Said. PSY 361 Learning Series. Cengage Learning.

Liu, C., Gwizdka, J., Liu, J., Xu, T., and Belkin, N. J. (2010). Analysis and evaluation of query reformulations in different task types. In Proceedings of the 73rd ASIS\&T Annual 
IX Congresso Brasileiro de Informática na Educação (CBIE 2020)

Anais do XXXI Simpósio Brasileiro de Informática na Educação (SBIE 2020)

Meeting on Navigating Streams in an Information Ecosystem - Volume 47, ASIS\&T '10, USA. American Society for Information Science.

Liu, C. and Song, X. (2018). How do information source selection strategies influence users' learning outcomes'. In Proceedings of the 2018 Conference on Human Information Interaction \& Retrieval, pages 257-260.

Lu, Y. and Hsiao, I.-H. (2017). Personalized information seeking assistant (pisa): from programming information seeking to learning. Information Retrieval Journal, 20:433455.

Machado, M., Pinelli, C., and Siqueira, S. (2019). A evolução da área de busca como um processo de aprendizagem com base em um mapeamento sistemático. In Anais dos Workshops do Congresso Brasileiro de Informática na Educação, page 833.

Mao, J., Liu, Y., Zhang, M., and Ma, S. (2016). How does domain expertise affect users' search processes in exploratory searches? In SAL@SIGIR, volume 1647.

Marchionini, G. (2018). Search, sense making and learning: closing gaps. Information and Learning Science, 120.

Meyers, E. M. (2018). When search is (mis) learning: Analyzing inference failures in student search tasks. Proceedings of the Association for Information Science and Technology, 55:357-366.

Moraes, F., Putra, S. R., and Hauff, C. (2018). Contrasting search as a learning activity with instructor-designed learning. In Proceedings of the 27th ACM International Conference on Information and Knowledge Management, pages 167-176. ACM.

Petticrew, M. and Roberts, H. (2008). Systematic reviews in the social sciences: A practical guide. John Wiley \& Sons.

Picciano, A. G. (2017). Theories and frameworks for online education: Seeking an integrated model. Online Learning, 21(3):166-190.

Pinelli, C., Tibau, M., and Siqueira, S. (2019). Google, se reordene e me ajude a aprender: Critérios de relevância para reordenar resultados de busca como um processo de aprendizagem. In Brazilian Symposium on Computers in Education (Simpósio Brasileiro de Informática na Educação-SBIE), volume 30, page 576.

Rieh, S. Y., Collins-Thompson, K., Hansen, P., and Lee, H.-J. (2016). Towards searching as a learning process: A review of current perspectives and future directions. Journal of Information Science, 42(1):19-34.

Rieh, S. Y., Kim, Y.-M., and Markey, K. (2012). Amount of invested mental effort (aime) in online searching. Information Processing \& Management, 48(6):1136-1150.

Schunk, D. H. (1991). Learning theories: An educational perspective. new york: Merrill.

Smith, C. L. and Rieh, S. Y. (2019). Knowledge-context in search systems: toward information-literate actions. In Proceedings of the 2019 Conference on Human Information Interaction and Retrieval, pages 55-62.

Syed, R. and Collins-Thompson, K. (2016). Optimizing search results for educational goals: Incorporating keyword density as a retrieval objective. In Second International Workshop on Search as Learning co-located with the 39th International ACM SIGIR Conference on Research and Development in Information Retrieval (SIGIR 2016), volume 1647.

Syed, R. and Collins-Thompson, K. (2018). Exploring document retrieval features associated with improved short- and long-term vocabulary learning outcomes. In CHIIR ' 18 Proceedings of the 2018 Conference on Human Information Interaction \& Retrieval, pages 191-200. 
IX Congresso Brasileiro de Informática na Educação (CBIE 2020)

Anais do XXXI Simpósio Brasileiro de Informática na Educação (SBIE 2020)

Taibi, D., Fulantelli, G., Marenzi, I., Nejdl, W., Rogers, R., and Ijaz, A. (2017). Sarweb: A semantic web tool to support search as learning practices and cross-language results on the web. In 2017 IEEE 17th International Conference on Advanced Learning Technologies (ICALT), pages 522-524.

Teixeira, C. P., Tibau, M., Siqueira, S. W. M., and Nunes, B. P. (2020). Reordering search results to support learning. In Popescu, E., Hao, T., Hsu, T.-C., Xie, H., Temperini, M., and Chen, W., editors, Emerging Technologies for Education, pages 361-369, Cham. Springer International Publishing.

Tibau, M., Siqueira, S. W., Nunes, B. P., Bortoluzzi, M., and Marenzi, I. (2018a). Modeling exploratory search as a knowledge-intensive process. In 2018 IEEE 18th International Conference on Advanced Learning Technologies (ICALT), pages 34-38. IEEE.

Tibau, M., Siqueira, S. W., Nunes, B. P., Bortoluzzi, M., Marenzi, I., and Kemkes, P. (2018b). Investigating users' decision-making process while searching online and their shortcuts towards understanding. In International Conference on Web-Based Learning, pages 54-64. Springer.

Vakkari, P. (2016). Searching as learning: A systematization based on literature. Journal of Information Science, 42(1):7-18.

Vakkari, P., Völske, M., Potthast, M., Hagen, M., and Stein, B. (2019). Modeling the usefulness of search results as measured by information use. Information Processing \& Management, 56:879-894.

Vygotsky, L., Cole, M., John-Steiner, V., Scribner, S., and Souberman, E. (1978). Mind in Society: Development of Higher Psychological Processes. Harvard University Press.

Weingart, N. and Eickhoff, C. (2016). Retrieval techniques for contextual learning. In SAL@SIGIR.

Williamson, B., Eynon, R., and Potter, J. (2020). Pandemic politics, pedagogies and practices: digital technologies and distance education during the coronavirus emergency. Learning, Media and Technology, 45(2):107-114.

Wilson, M. J. and Wilson, M. L. (2013). A comparison of techniques for measuring sensemaking and learning within participant-generated summaries. Journal of the American Society for Information Science and Technology, 64:291-306.

Wilson, M. L., Ye, C., Twidale, M. B., Grasse, H., Rosenthal, J., and McKittrick, M. (2016). Search literacy: Learning to search to learn. In SAL@SIGIR, volume 1647.

Wilson, T. D. (1999). Models in information behaviour research. Journal of Documentation, 55:249-270.

Yu, R., Gadiraju, U., and Dietze, S. (2018a). Detecting, understanding and supporting everyday learning in web search. arXiv preprint arXiv:1806.11046.

Yu, R., Gadiraju, U., Holtz, P., Rokicki, M., Kemkes, P., and Dietze, S. (2018b). Predicting user knowledge gain in informational search sessions. In SIGIR '18 The 41st International ACM SIGIR Conference on Research \& Development in Information Retrieval, pages 75-84.

Zapata, A., Menéndez, V. H., Prieto, M. E., and Romero, C. (2015). Evaluation and selection of group recommendation strategies for collaborative searching of learning objects. International Journal of Human-Computer Studies, 76:22 - 39.

Zhang, X. (2017). User perceived learning from interactive searching on big medical literature data. Big Data \& Information Analytics, 2(2380-6966_2017_5_10):1.

Zhuang, M., Toms, E. G., and Demartini, G. (2016). Search behaviour before and after search success. In CEUR Workshop Proceedings, volume 1647. RheinischWestfaelische Technische Hochschule Aachen* Lehrstuhl Informatik V. 